Article

\title{
Products of Hexavalent Chromium Reduction by Green Rust Sodium Sulfate and Associated Reaction Mechanisms
}

\author{
Andrew N. Thomas ${ }^{1, *}$, Elisabeth Eiche ${ }^{1}$, Jörg Göttlicher ${ }^{2}$, Ralph Steininger ${ }^{2}$, \\ Liane G. Benning ${ }^{3,4}\left(\mathbb{D}\right.$, Helen M. Freeman ${ }^{3,+} \mathbb{D}$, Knud Dideriksen ${ }^{5}$ and Thomas Neumann 6 \\ 1 Institute for Applied Geosciences, Karlsruhe Institute of Technology, Adenauerring 20b, Building 50.40, \\ 76135 Karlsruhe, Germany; elisabeth.eiche@kit.edu \\ 2 Institute for Synchrotron Radiation, Karlsruhe Institute of Technology, Herman-von-Helmholtz Platz 1, \\ 76344 Eggenstein-Leopoldshafen, Germany; joerg.goettlicher@kit.edu (J.G.); ralph.steininger@kit.edu (R.S.) \\ 3 GFZ German Research Center for Geosciences, Telegrafenberg, 14473 Potsdam, Germany; \\ benning@gfz-potsdam.de (L.G.B.); h.m.freeman@leeds.ac.uk (H.M.F.) \\ 4 Department of Earth Sciences, Free University of Berlin, 12249 Berlin, Germany \\ 5 Nano-Science Center, Department of Chemistry, University of Copenhagen, Universitetsparken 5, \\ 2100 Copenhagen, Denmark; knud@nano.ku.dk \\ 6 Department of Applied Geosciences, Technical University of Berlin, Ernst-Reuter-Platz 1, \\ 10587 Berlin, Germany; neumann@tu-berlin.de \\ * Correspondence: andrew.thomas@kit.edu \\ + Current address: School of Chemical and Process Engineering, University of Leeds, Leeds LS29JT, UK.
}

Received: 28 September 2018; Accepted: 25 October 2018; Published: 29 October 2018

check for updates

\begin{abstract}
The efficacy of in vitro $\mathrm{Cr}(\mathrm{VI})$ reduction by green rust sulfate suggests that this mineral is potentially useful for remediation of $\mathrm{Cr}$-contaminated groundwater. Previous investigations studied this reaction but did not sufficiently characterize the intermediates and end products at chromate $\left(\mathrm{CrO}_{4}{ }^{2-}\right)$ concentrations typical of contaminant plumes, hindering identification of the dominant reaction mechanisms under these conditions. In this study, batch reactions at varying chromate concentrations and suspension densities were performed and the intermediate and final products of this reaction were analyzed using X-ray absorption spectroscopy and electron microscopy. This reaction produces particles that maintain the initial hexagonal morphology of green rust but have been topotactically transformed into a poorly crystalline Fe(III) oxyhydroxysulfate and are coated by a $\mathrm{Cr}$ (oxy) hydroxide layer that results from chromate reduction at the surface. Recent studies of the behavior of $\mathrm{Cr}$ (III) (oxy) hydroxides in soils have revealed that reductive transformation of $\mathrm{CrO}_{4}{ }^{2-}$ is reversible in the presence of $\mathrm{Mn}(\mathrm{IV})$ oxides, limiting the applicability of green rust for Cr remediation in some soils. The linkage of $\mathrm{Cr}$ redox speciation to existing Fe and Mn biogeochemical cycles in soils implies that modification of green rust particles to produce an insoluble, $\mathrm{Cr}$ (III)-bearing Fe oxide product may increase the efficacy of this technique.
\end{abstract}

Keywords: green rust sulfate; chromium; EXAFS; metal redox cycles

\section{Introduction}

Chromium contamination of groundwater is a common environmental problem worldwide and poses a major threat to human health due to the toxicity, carcinogenicity, and solubility of its hexavalent form. Chromium is released into the environment by industrial processes such as metal plating, wood treatment, and leather tanning [1] and exists in several oxidation states from 0 to +6 , the most common of which are $\mathrm{Cr}(\mathrm{III})$ and $\mathrm{Cr}(\mathrm{VI})$, which usually takes the form of the chromate oxyanion $\left(\mathrm{CrO}_{4}{ }^{2-}\right)$. 
$\mathrm{Cr}(\mathrm{VI})$, due to its carcinogenicity, toxicity, and mobility, is hazardous even at low concentrations. Trivalent chromium, on the other hand, is an essential trace element for sugar metabolism [2] and normally does not exist at high enough concentrations to have toxic effects due to its low solubility [3] and tendency to form stable complexes with soil minerals [4]. Therefore, reductive transformation of $\mathrm{CrO}_{4}{ }^{2-}$ to $\mathrm{Cr}^{3+}$ is a promising remediation strategy. Several viable remediation methods exist that are capable of driving this transformation, including $\mathrm{Fe}^{2+}$ and dithionite [5], zero-valent iron [6-8], and green rust, a layered Fe(II)-Fe(III) hydroxide mineral. However, several recent studies [9-11] have investigated the regeneration of chromate from $\mathrm{Cr}$ (III) and $\mathrm{Cr}$ (III)-bearing $\mathrm{Fe}$ (III) hydroxides in packed column experiments. These studies revealed that biogenic $\mathrm{Mn}(\mathrm{IV})$ oxides are the primary oxidant in these systems and that reductive transformation of chromate in soils may be reversible, depending on the Mn content and redox conditions of the soils as well as the solubility of the $\mathrm{Cr}$ (III)-bearing phase. Therefore, the use of reactive particles, such as green rust, with heterogeneous reaction mechanisms and the potential to produce less-soluble $\mathrm{Cr}$ (III)-bearing solid solutions is investigated here as a potential means of remediating chromium contamination.

Green rust, a member of the layered double hydroxide (LDH) family, is composed of repeating, positively charged $\mathrm{Fe}(\mathrm{II})-\mathrm{Fe}(\mathrm{III})$ hydroxide sheets that alternate with an interlayer containing water, an interlayer anion, and occasionally an interlayer cation [12]. Green rusts are classified based on the identity of the interlayer anion, the most common of which are $\mathrm{CO}_{3}{ }^{2-}, \mathrm{Cl}^{-}$, and $\mathrm{SO}_{4}{ }^{2-}$. Originally identified in hydric soils as fougèrite [13], it is stable within a narrow redox potential range, but destabilizes at low $(<6)$ or very high $\mathrm{pH}$ values [14] and under oxidizing conditions. Green rust has also been identified as an oxidation product of zero-valent iron (ZVI) in permeable reactive barriers [15] and as a product of steel corrosion in marine environments [16].

The ability of green rust to remediate $\mathrm{As}$ [17-19], $\mathrm{NO}_{3}{ }^{-}$[20], $\mathrm{NO}_{2-}$ [21], $\mathrm{Se}(\mathrm{VI})$ [22,23], U(VI) [24], $\mathrm{Np}$ [25], and $\mathrm{Cr}(\mathrm{VI})$ [26-31] has been investigated extensively, with mixed results. The kinetics and byproducts of the $\mathrm{Cr}(\mathrm{VI})$-green rust reaction have been investigated repeatedly, but the resulting product characterizations and mechanism descriptions vary, most likely due to inconsistent synthesis methods and analytical methodologies. The twin studies of Loyaux-Lawniczak et al. (1999) [26] and Loyaux-Lawniczak et al. (2000) [27] examined the solid byproducts of green rust chloride and sulfate reacted with $\mathrm{CrO}_{4}{ }^{2-}$ using X-ray diffraction (XRD), Raman spectroscopy, and X-ray photoelectron spectroscopy (XPS): the product was identified as a poorly ordered $\mathrm{Cr}$ (III)-Fe(III) oxyhydroxide resembling 2-line ferrihydrite. Bond and Fendorf (2003) [28] reduced chromate with green rust sulfate, carbonate and chloride and proposed a dominant interlayer-exchange mechanism for the reaction. Extended X-ray absorption fine structure spectroscopy (EXAFS) scans of the products suggested the formation of a poorly ordered Cr(III)-Fe(III) oxyhydroxide. Williams and Scherer (2001) [29] and Legrand et al. (2004) [30] measured the kinetics of chromate reduction by green rust carbonate and identified the product as a Fe(III) oxyhydroxycarbonate. Finally, Skovbjerg et al. (2006) [31] reacted concentrated chromate solutions with freshly prepared, untreated green rust sulfate and analyzed both partially and fully reacted solid samples. This study identified $\mathrm{Cr}$ (III)-bearing goethite as the primary reaction product, formed via chromate exchange for sulfate in the interlayer.

Although the reduction of chromate by green rust is well-characterized, what is missing is both a detailed structural study of the byproducts and an evaluation of the mechanism of green rust oxidation at chromate concentrations characteristic of contaminant plumes. EXAFS shell fits of byproducts of this reaction are available [28], but these shell-by-shell fits are better suited for less-complex samples. Samples with multiple mineral components are often better characterized by linear combination fitting (LCF) of the $k^{3}$-weighted EXAFS region using synthesized reference standards, especially for substances with modular, repeating structural geometries (such as iron oxides). In addition, although Bond and Fendorf (2003) [28] reacted green rust with $\mathrm{Cr}$ concentrations characteristic of contaminant plumes $(192 \mu \mathrm{M})$ and Skovbjerg et al. (2006) [31] characterized intermediate products of reactions with higher $\mathrm{Cr}$ concentrations $(0.8-12.3 \mathrm{mM})$, intermediate products of batch reactions at plume concentrations have not been analyzed, so little is known about the reaction mechanism under these 
conditions. Without knowledge of the structure of the Cr-bearing solids formed by this reaction and the mechanism of formation, the long-term stability of $\mathrm{Cr}$ immobilized by green rust in permeable reactive barriers becomes very difficult to predict.

The objective of the present study was to determine the structure and stability of the Cr-bearing products of green rust reacted with $\mathrm{Cr}(\mathrm{VI})$ at typical plume concentrations. Synthetic green rust was oxidized to completion by solutions of chromate at concentrations between 30 and $1300 \mu \mathrm{M}$. By adding freshly prepared green rust suspension and a chromate stock solution at a ratio sufficient to oxidize $100 \%$ of the green rust to varying volumes of water, the initial chromate concentrations and green rust suspension densities were varied systematically, allowing the analysis of products formed at different variable reaction rates. EXAFS, transmission electron microscopy (TEM), and scanning electron microscopy (SEM) were then used to characterize the intermediate and end products. This allowed us to determine the dominant reaction mechanism(s) as well as how these mechanisms vary under different reaction conditions.

\section{Materials and Methods}

Green rust sulfate $\left[\mathrm{Fe}_{4}{ }_{4} \mathrm{Fe}^{\mathrm{III}}{ }_{2}(\mathrm{OH})_{12} \mathrm{SO}_{4} \cdot 2 \mathrm{H}_{2} \mathrm{O}\right]$ was synthesized using a modified version of the co-precipitation method from Géhin et al. (2002) [32]. After deoxygenating solutions of $\mathrm{FeSO}_{4} \cdot 7 \mathrm{H}_{2} \mathrm{O}$ and $\mathrm{Fe}_{2}\left(\mathrm{SO}_{4}\right)_{3} \cdot \mathrm{H}_{2} \mathrm{O}$ in doubly-deionized water (Siemens Milli-Q Plus, Lowell, Massachusetts, USA) by purging the solutions with $\mathrm{N}_{2}$, both solutions were transferred into a glovebox (Jacomex P[Box] Compact Glove Box, Dagneux, France) under an Ar atmosphere. In the glovebox, the Fe(III) solution was added to the Fe(II) solution using a peristaltic pump (Ismatec IPC, Wertheim, Germany) at a constant rate of approximately $1 \mathrm{~mL} / \mathrm{min}$ for $40 \mathrm{~min}$ while mixing with a magnetic stirrer to maintain solution homogeneity. The solution $\mathrm{pH}$ was maintained at approximately 7.0 using dropwise addition of $1 \mathrm{M} \mathrm{NaOH}$. This method allowed the synthesis of a product with a known [Fe(II)] primarily bound in the solid fraction, and a minimal amount of side products (see Supplementary Information for explanation). After complete mixing of the two solutions, the mixture had a [Fe(II)]/[Fe(III)] ratio of 2 and the total $[\mathrm{Fe}]$ was approximately $0.1 \mathrm{M}$.

After aging the product for $24 \mathrm{~h}$, one batch was collected by vacuum filtration using a Whatman $0.2 \mu \mathrm{m}$ nylon membrane filter and protected from oxidation by adding glycerol. XRD measurements were obtained using a Bruker D8 Diffractometer (Karlsruhe, Germany) equipped with the EVA 100 software. $X$-rays were emitted from a Cu-K $\alpha$ source $(\lambda=1.5418 \AA)$, and data were collected at $2 \theta$ values between $2-82^{\circ}$ with a step size of $0.02^{\circ}$ and an average counting time of $1 \mathrm{~s}$ per step.

To vary the reaction rate between $\mathrm{CrO}_{4}{ }^{2-}$ and green rust sulfate, equimolar amounts of each reagent were diluted in variable volumes of a $13.33 \mathrm{mmol} \mathrm{kg}^{-1} \mathrm{Na}_{2} \mathrm{SO}_{4}$ solution, producing solutions with $\left[\mathrm{CrO}_{4}{ }^{2-}\right]$ varying from 0.033 to $1.333 \mathrm{mmol} \mathrm{kg}^{-1}$ (see Table 1). Prior to the addition of green rust, the $\mathrm{pH}$ of the $\mathrm{CrO}_{4}{ }^{2-}$ solutions and the green rust sulfate suspension were adjusted to 7.0, where geochemical modelling (PHREEQC) indicates that the dichromate $\left(\mathrm{Cr}_{2} \mathrm{O}_{7}{ }^{2-}\right)$ concentration is negligible. Approximately $30 \mathrm{mg}$ of green rust were then added to the $\mathrm{CrO}_{4}{ }^{2-}$ solutions as a suspension without drying or any other treatment. Separate batches of each $\mathrm{CrO}_{4}{ }^{2-}$ solution were reacted for $24 \mathrm{~h}$ or 7 days before termination of the reaction by vacuum filtration through a $0.2 \mu \mathrm{m}$ nylon membrane filter (Whatman, Little Chalfont, UK). A third batch was reacted to measure the $\mathrm{CrO}_{4}{ }^{2-}$ reduction kinetics, and a fourth to collect samples for electron microscopy. Samples of the reaction suspension were diluted in $0.01 \mathrm{M} \mathrm{HCl}$ and filtered using a $0.2 \mu \mathrm{m}$ syringe filter. A $30 \mathrm{mg}$ sample of green rust was also suspended in the $13.33 \mathrm{mmol} \mathrm{kg}^{-1}$ diluent as a blank and characterized by XRD (see previous section). 
Table 1. Approximate $\mathrm{CrO}_{4}{ }^{2-}$ concentrations and green rust suspension densities of the six reaction solutions. All samples diluted in $13.3 \mathrm{mmol} \mathrm{kg}^{-1} \mathrm{Na}_{2} \mathrm{SO}_{4}$.

\begin{tabular}{cccc}
\hline Solution & Volume $(\mathbf{m L})$ & {$\left[\mathrm{CrO}_{\mathbf{4}}{ }^{\mathbf{2}}\right] \mathbf{( \mathbf { m g ~ L } ^ { - \mathbf { 1 } } )}$} & Green Rust Suspension Density $\left(\mathbf{m g ~ L ~}^{-\mathbf{1}}\right)$ \\
\hline $\mathrm{C} 1$ & 50 & 69 & 600 \\
$\mathrm{C} 2$ & 100 & 35 & 300 \\
$\mathrm{C} 3$ & 250 & 14 & 120 \\
$\mathrm{C} 4$ & 500 & 6.9 & 60 \\
$\mathrm{C} 5$ & 1000 & 3.5 & 30 \\
$\mathrm{C} 6$ & 2000 & 1.7 & 15 \\
\hline
\end{tabular}

Aqueous $\mathrm{CrO}_{4}{ }^{2-}$ concentrations were determined by colorimetric analyses of the filtered solutions using the 1,5-diphenylcarbazide method Environmental Protection Agency (EPA) Method 7196A) with a Perkin-Elmer Lambda 2S UV-Vis Spectrophotometer (Waltham, MA, USA) calibrated using a four-point calibration curve. The $\mathrm{pH}$ of the reaction system after 7 days was measured using a Wissenschaftlich-Technische-Werkstätten (WTW) pH 330 pH meter (Weilheim, Germany).

EXAFS spectra of all $24 \mathrm{~h}$ and 7 day reacted samples were obtained on beamline SUL-X (wiggler $X$-ray source) at the ANKA synchrotron facility in Eggenstein-Leopoldshafen, Germany. Data reduction and analysis of the EXAFS spectra were performed using the Athena/Artemis software package (Ravel \& Newville, 2005) [33]. All Fe reference compounds were synthesized according to the standard synthesis protocols in Cornell \& Schwertmann (2008) [34]. The experimental details and data analysis steps are outlined in the Supplementary Information.

All electron microscopy experiments were performed at the Potsdam Imaging and Spectral Analysis (PISA) facility at the Deutsches Geoforschungszentrum (GFZ) in Potsdam, Germany. Samples were collected from reaction $\mathrm{C} 1$ after $5 \mathrm{~s}$ (halfway point of the reaction), 1 min (reaction completion point) and 7 days of aging, and from reaction $\mathrm{C} 6$ after $1 \mathrm{~min}$ (halfway point of the reaction), $10 \mathrm{~min}$ (reaction completion point) and 7 days of aging.

TEM samples were prepared by drop casting the diluted suspension onto a $3 \mathrm{~mm} \mathrm{Cu}$-TEM grid coated with holey carbon film, which was then transferred to a single-tilt holder inside the anaerobic chamber. The sample holder was then transferred to the TEM instrument within $30 \mathrm{~s}$ to minimize the effects of oxidation. Imaging and analysis were done using a FEI Tecnai TEM (Thermo Fisher Scientific, Waltham, MA, USA) at $200 \mathrm{kV}$ equipped with a Gatan Tridiem imaging filter (GIF), an energy dispersive X-ray (EDX) analyzer, to measure chemical composition, and a Gatan Orius SC200D 4K pixel cooled charge-coupled device (CCD) camera (Pleasanton, CA, USA). Selected-Area Electron Diffraction (SAED) patterns were collected using an aperture with an effective diameter of $250 \mathrm{~nm}$ at the image plane and a camera length of $990 \mathrm{~mm}$. The SAED patterns were developed in a Ditabis Imaging Plate Scanner (Munich, Germany). TEM images were processed and converted using Gatan DigitalMicrograph, while the raw EDX data was processed using EDX Quant.

SEM samples were prepared by vacuum filtration of small volumes of suspended sample followed by adhesion of the filter paper to the SEM sample holder with carbon tape and quickly coated with carbon using BAL-TEC MED 020 (Leica Microsystems, Wetzlar, Germany) to avoid charging effects during imaging. Images were obtained using a Zeiss Ultra Plus Field Emission-Scanning Electron Microscope (FE-SEM) (Carl Zeiss AG, Oberkochen, Germany) in a high vacuum mode at acceleration voltages between 1 and $3 \mathrm{kV}$ with $10 \mu \mathrm{m}$ aperture size using an InLens secondary electron detector. Elemental analyses of the samples were performed at $20 \mathrm{kV}$ with $120 \mu \mathrm{m}$ aperture size in point and shoot mode using a Thermo Scientific Ultra Dry Energy Dispersive Spectrometry (EDX) detector (Waltham, MA, USA). 


\section{Results}

\subsection{Characterization and Stability of Sulfate Green Rust}

The X-ray diffractogram of the aged synthetic green rust sulfate stabilized with glycerol is shown in Figure 1a. No side products were observed by this method, but the green rust basal plane (003) peak at $\sim 8^{\circ} 2 \theta$ is smaller in intensity relative to other green rust XRD patterns from the literature [32,35]. When suspended in $13.33 \mathrm{mM} \mathrm{Na}_{2} \mathrm{SO}_{4}$ (the same ionic strength as the reaction solutions), the synthetic sulfate green rust transformed to the product shown in Figure 1b. This product is dominated by a poorly crystalline phase (most likely ferrihydrite), but peaks corresponding to magnetite and sulfate green rust were also identified. The green rust basal plane reflection at $\sim 8^{\circ} 2 \theta$ is not visible, possibly because the thick layer of glycerol added to stabilize the product disproportionally decreased reflection at low incident angles.

\section{2. $\mathrm{CrO}_{4}^{2-}$ Reduction Kinetics}

The time required to reduce $\mathrm{Cr}(\mathrm{VI})$ to completion showed a strong dependence on the initial $\mathrm{Cr}(\mathrm{VI})$ concentration (Figure 2). At higher concentrations (C1-C3), the $\mathrm{CrO}_{4}{ }^{2-}$ was reduced to completion within five minutes, while at lower $\mathrm{CrO}_{4}{ }^{2-}$ concentrations (C4-C6), complete reduction took 5-6 times as long. Minimal sorption of $\mathrm{CrO}_{4}{ }^{2-}$ to the glass beaker was shown by the blank solution, and $\mathrm{CrO}_{4}{ }^{2-}$ concentrations remained low until the reaction was terminated after 7 days. In all reaction systems, the $\mathrm{pH}$ value had decreased to between 4 and 5 by the time the reaction was terminated after 7 days.

\subsection{Fe and Cr Speciation}

The lack of the characteristic $\mathrm{Cr}(\mathrm{VI}) 1 \mathrm{~s} \rightarrow 3 \mathrm{~d}$ pre-edge peak at $5993 \mathrm{eV}$ in all 7-day reacted spectra in Figure 3 suggests that there was not a significant level of $\mathrm{Cr}(\mathrm{VI})$ in any of the samples, as would be the case if the $\mathrm{CrO}_{4}{ }^{2-}$ had simply adsorbed onto the surface of the product.

Fe EXAFS linear combination fits $\left(k^{3}\right.$-weighted, Table 2$)$ were obtained by fitting the Fe EXAFS data of the 24-h (Figure 4a) and 7-day (Figure 4b) samples to a set of reference standards. In every fitted sample, the dominant detected Fe-bearing phase was feroxyhyte $\left(\delta^{\prime}-\mathrm{FeOOH}\right)$, the proportion of which increases in all reactions except $\mathrm{C} 5$ between $24 \mathrm{~h}$ and 7 days. Ferrihydrite was detected at very low levels in some samples, albeit the patterns for ferrihydrite and feroxyhyte were similar. Ferrihydrite EXAFS spectra vary with the preparation method used [36], and patterns for ferrihydrite have been published [37] that more closely align with our feroxyhyte patterns than our ferrihydrite patterns do. The other phases identified by EXAFS are goethite $(\alpha-\mathrm{FeOOH})$ and lepidocrocite $(\gamma-\mathrm{FeOOH})$, the last of which contributes more to the overall fit at the expense of the goethite and feroxyhyte-like components as the initial $\mathrm{CrO}_{4}{ }^{2-}$ concentration decreases. 

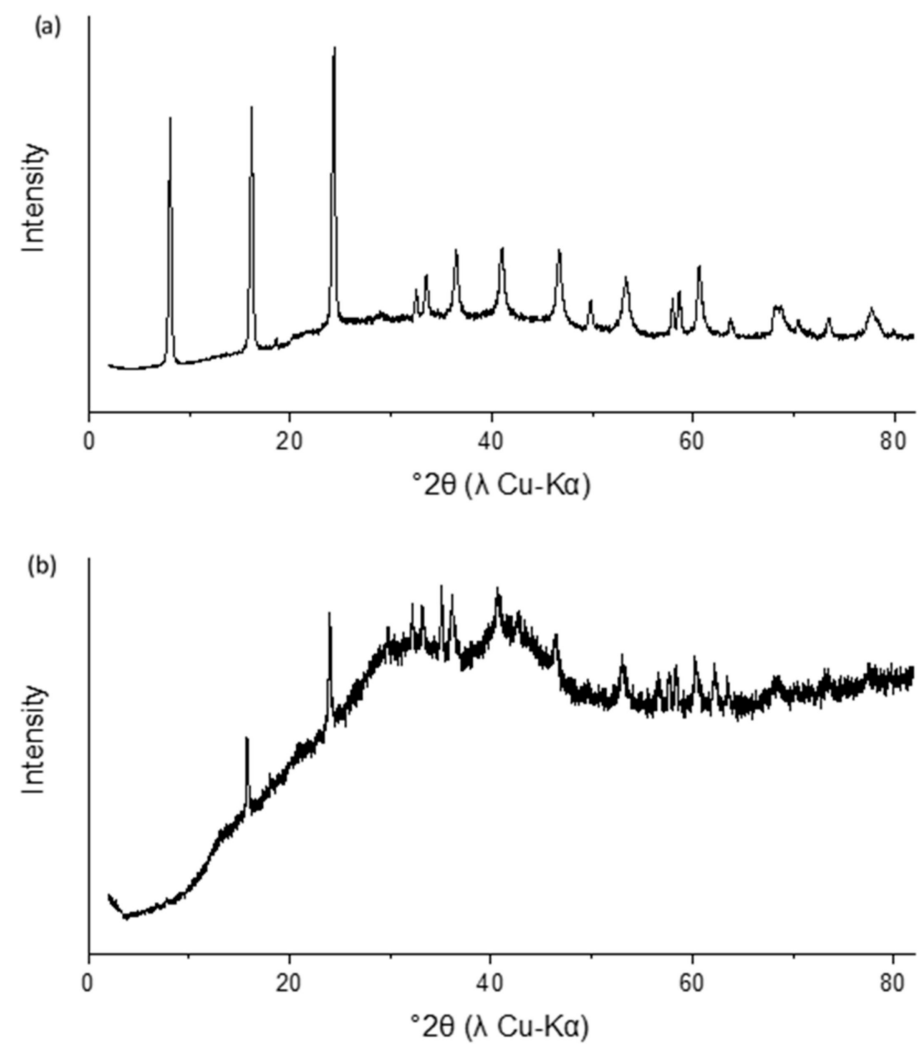

Figure 1. XRD trace of synthetic green rust sulfate (a) and green rust suspended in aqueous $\mathrm{Na}_{2} \mathrm{SO}_{4}$ for seven days (b). Transformation products include ferrihydrite and magnetite.

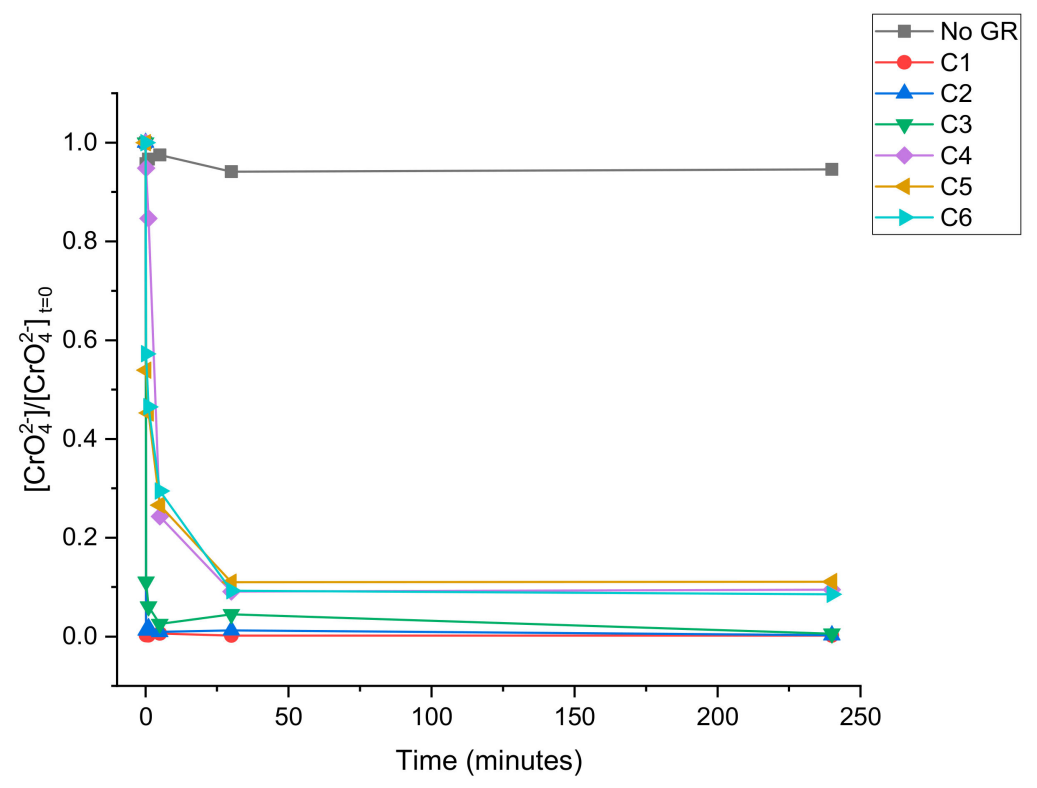

Figure 2. Reduction of $\mathrm{Cr}(\mathrm{VI})$ at variable initial $\mathrm{CrO}_{4}{ }^{2-}$ initial concentrations and green rust suspension densities (see Table 1). Blank reaction with no green rust added also included. All measurements were performed on a single batch reaction. 


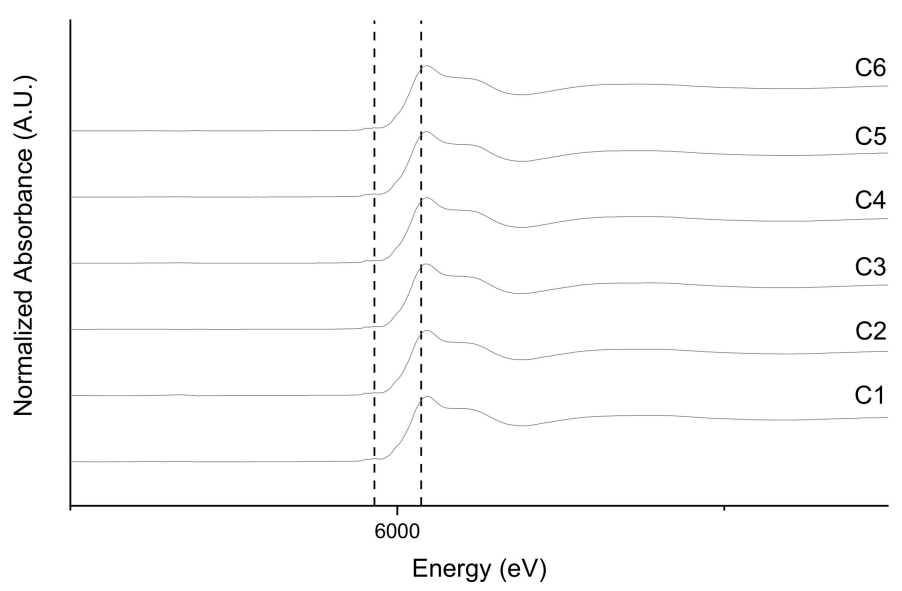

Figure 3. Cr XANES spectrum showing absence of $\mathrm{Cr}(\mathrm{VI})$ pre-edge peak (at $5993 \mathrm{eV}$ ) and the dominance of the $\mathrm{Cr}(\mathrm{III})$ peak (at $6007.3 \mathrm{eV}$ ) in samples reacted for 7 days.

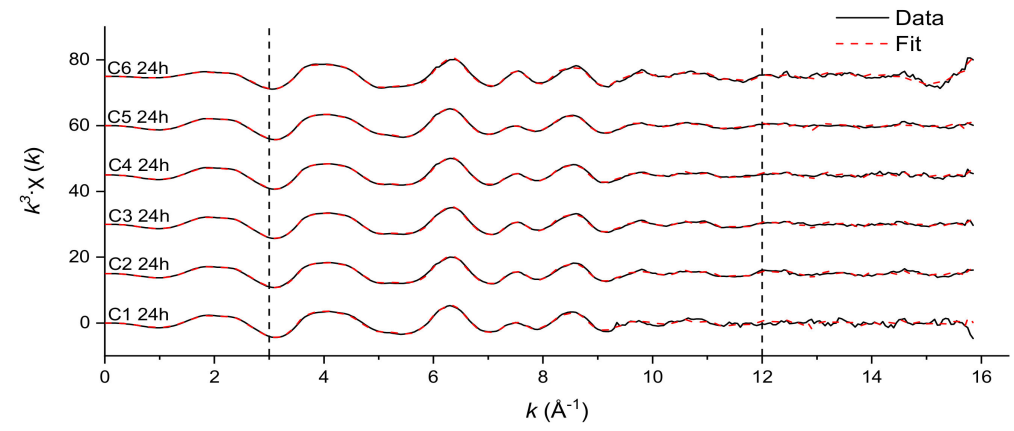

(a)

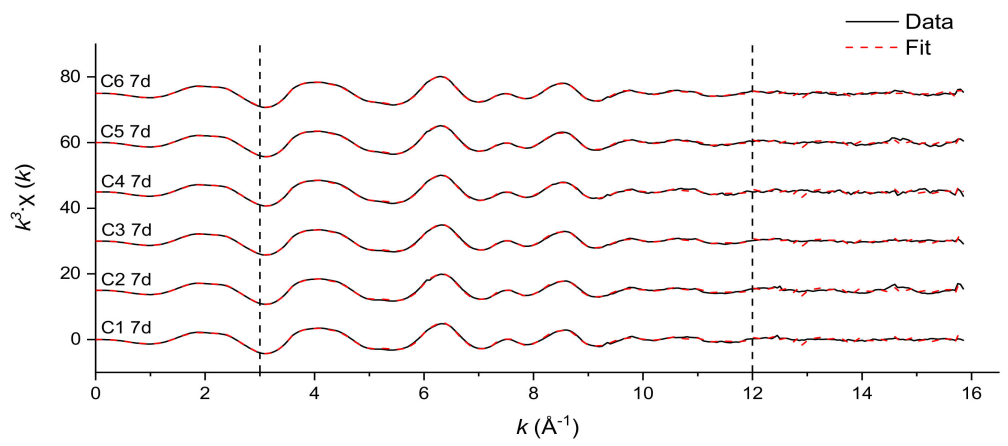

(b)

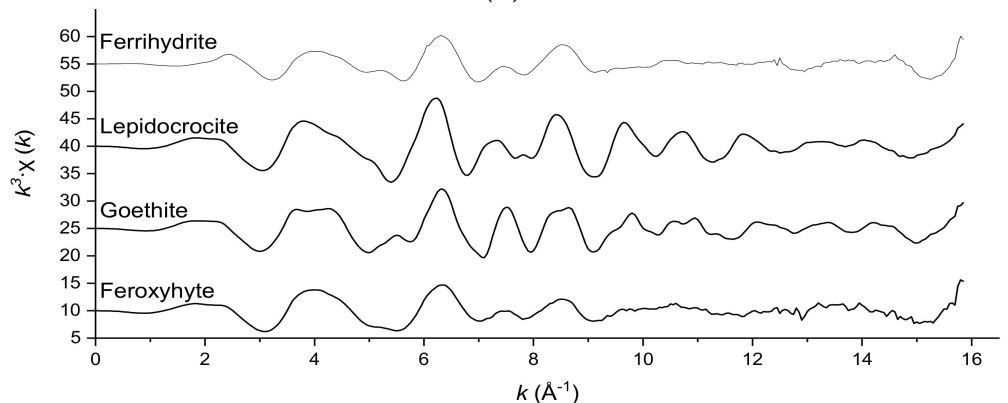

(c)

Figure 4. Fe $k^{3}$-weighted EXAFS spectra of samples aged for 7 days (a) and $24 \mathrm{~h}$ (b). Fits are linear combinations of the reference standards in (c). The vertical dashed lines represent the fit boundaries. 
Table 2. Fe linear combination fit results and statistics of samples collected after $24 \mathrm{~h}$ and $7 \mathrm{~d}$ reaction time. Fits were constrained to no more than four standards.

\begin{tabular}{cccccccc}
\hline & Weights & \multicolumn{7}{c}{} \\
\hline Sample & Feroxyhyte & Goethite & Lepidocrocite & Ferrihydrite & Sum & R-Factor & Reduced $\chi^{2}$ \\
\hline C1 24 h & 0.813 & 0.112 & 0.064 & 0.073 & 1.063 & 0.024 & 0.122 \\
C1 7 d & 0.902 & 0.139 & 0 & 0 & 1.041 & 0.0105 & 0.0476 \\
C2 24 h & 0.741 & 0.229 & 0.032 & 0 & 1.002 & 0.01 & 0.0472 \\
C2 7 d & 0.909 & 0.115 & 0.016 & 0.003 & 1.0 & 0.0114 & 0.0521 \\
C3 24 h & 0.746 & 0.243 & 0.027 & 0 & 1.016 & 0.0090 & 0.0435 \\
C3 7 d & 0.874 & 0.128 & 0.028 & 0 & 1.03 & 0.00656 & 0.0297 \\
C4 24 h & 0.794 & 0.181 & 0.047 & 0 & 1.022 & 0.00748 & 0.0355 \\
C4 7 d & 0.906 & 0.085 & 0.052 & 0.002 & 1.044 & 0.0099 & 0.046 \\
C5 24 h & 0.827 & 0.075 & 0.104 & 0.02 & 1.027 & 0.00513 & 0.0242 \\
C5 7 d & 0.809 & 0.075 & 0.096 & 0.059 & 1.039 & 0.00631 & 0.0303 \\
C6 24 h & 0.531 & 0.39 & 0.033 & 0 & 0.953 & 0.019 & 0.0934 \\
C6 7 d & 0.824 & 0.075 & 0.12 & 0.001 & 1.02 & 0.00452 & 0.0214 \\
\hline
\end{tabular}

Table 3 shows the calculated parameters of the Cr EXAFs shell fits shown in Figure 5. The coordination numbers of the $\mathrm{Cr}-\mathrm{O}$ and first $\mathrm{Cr}-\mathrm{Cr}$ shells are fixed to literature values [38] confirmed during preliminary fits of the region $\mathrm{R}=1.2$ to 3 . The outer shells were fit using pathways calculated from the $\mathrm{Cr}$-substituted lepidocrocite $(\gamma-\mathrm{FeOOH})$ structure, in which $\mathrm{MeO}_{6}$ octahedra share edges and single corners, corresponding to $\mathrm{Cr}$ - $\mathrm{Cr}$ distances of 3.05 and $3.98 \AA$, respectively. The corner-sharing contribution at $3.98 \AA$ A has a coordination number between 1.5 and 2.5 in all samples, corresponding to the $\gamma$-MeOOH local structure typical of poorly crystalline $\mathrm{Cr}$ hydroxides, particularly those on $\mathrm{Fe}$ oxide surfaces $[39,40]$. 
Table 3. Fitting parameters derived from Cr EXAFS analysis of reaction products. $\mathrm{N}$ is the degeneracy of each shell, R is the interatomic distance, and $\sigma^{2}$ is the Debye-Waller parameter. Parameters marked with an asterisk $\left(^{*}\right)$ were kept fixed during fitting, while parameters marked § were constrained so that parameters from different shells shared the same value. R-factor reported to indicate goodness of fit.

\begin{tabular}{|c|c|c|c|c|c|c|c|c|c|c|}
\hline Sample & & $\mathrm{Cr}-\mathrm{O}$ & & Edge: & $\mathrm{Cr}-\mathrm{Cr}$ & & Single Corner: & $\mathrm{Cr}-\mathrm{Cr}$ & & $R(\%)$ \\
\hline & $\mathrm{N}$ & $\mathrm{R}(\AA)$ & $\sigma^{2}\left(\AA^{2}\right)$ & $\mathrm{N}$ & $\mathrm{R}(\AA)$ & $\sigma^{2}\left(\AA^{2}\right) \S$ & $\mathrm{N} \pm 50 \%$ & $\mathrm{R}(\AA)$ & $\sigma^{2}\left(\AA^{2}\right) \S$ & \\
\hline $\mathrm{C} 17 \mathrm{~d}$ & $6 *$ & 1.97 & $0.0021 \pm 0.0006$ & $3 *$ & 3.06 & $0.011 \pm 0.0028$ & 2.53 & 3.92 & $0.011 \pm 0.0028$ & 1.97 \\
\hline $\mathrm{C} 27 \mathrm{~d}$ & $6 *$ & 1.96 & $0.0023 \pm 0.0006$ & $3 *$ & 3.05 & $0.011 \pm 0.0026$ & 2.79 & 3.92 & $0.011 \pm 0.0026$ & 1.87 \\
\hline $\mathrm{C} 37 \mathrm{~d}$ & $6 *$ & 1.96 & $0.0019 \pm 0.0007$ & $3 *$ & 3.04 & $0.011 \pm 0.0032$ & 2.64 & 3.92 & $0.011 \pm 0.0032$ & 2.17 \\
\hline $\mathrm{C} 47 \mathrm{~d}$ & $6 *$ & 1.97 & $0.0027 \pm 0.0006$ & $3 *$ & 3.04 & $0.0104 \pm 0.0023$ & 1.84 & 3.89 & $0.0104 \pm 0.0023$ & 1.95 \\
\hline $\mathrm{C} 57 \mathrm{~d}$ & $6 *$ & 1.97 & $0.0022 \pm 0.0006$ & $3 *$ & 3.03 & $0.01 \pm 0.0022$ & 1.76 & 3.89 & $0.01 \pm 0.0022$ & 1.92 \\
\hline C6 $7 \mathrm{~d}$ & $6 *$ & 1.97 & $0.0026 \pm 0.0006$ & $3 *$ & 3.03 & $0.01 \pm 0.0023$ & 1.79 & 3.88 & $0.01 \pm 0.0023$ & 2.15 \\
\hline
\end{tabular}




\subsection{Electron Microscopy}

TEM images and SAED patterns were collected for material sampled at regular intervals during the reactions of green rust with solutions $\mathrm{C} 1$ and C6 (Figures 6 and 7). Each sample contained hexagonal plates up to $400-500 \mathrm{~nm}$ in size and up to $20 \mathrm{~nm}$ thick. After $5 \mathrm{~s}$, reaction C1 results in a mixture of particles with hexagonal and rod-like morphologies (Figure 6a). These particles appear to be associated with each other, although no specific boundaries of the type observed by Skovbjerg et al. (2006) are seen. After $1 \mathrm{~min}$ of reaction time, when the green rust has been fully oxidized, the product is again dominated by wide hexagonal particles and smaller rod-like particles, which are either separated from the hexagons or located near their edges. SAED patterns for $\mathrm{C} 1$ samples after $1 \mathrm{~min}$ of aging (Figure 6b) show two sets of diffuse spots arranged hexagonally, corresponding to Bragg diffraction with d-values of $\sim 2.5$ and $\sim 1.7 \AA$. The d-values roughly match the 330 and 300 spacings of green rust (accounting for slight changes in spacing due to differences in the $\mathrm{Fe}(\mathrm{II})$ and $\mathrm{Fe}(\mathrm{III})$ ionic radii) identified by Christiansen et al. (2009) [41], indicating that aspects of the original structure in the 100 direction has been preserved. Rod-like particles incorporated into the hexagonal particles are also visible in the SEM images. After 7 days of aging, the boundaries of the hexagonal particles have roughened and very faint SAED spots corresponding to the same spacings can be seen (pattern in the inset has been enhanced for visibility). Both the SEM and TEM images indicate that rod-like particles are still incorporated into the structure, and the SEM images of the particles show that they have become thicker and have a rough, amorphous surface (Figure 6c).

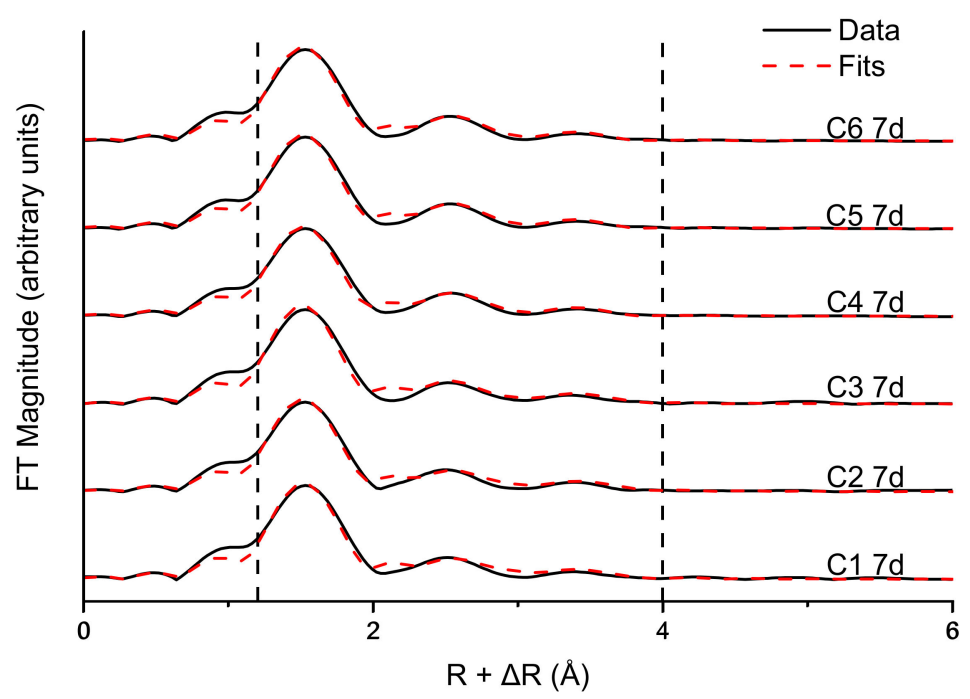

Figure 5. Fourier-transformed Cr EXAFS spectra and fits of all samples after 7 days. All data were fit over the range $k=3$ to $10.5 \AA^{-1}$ due to noise at high $\mathrm{k}$ in some samples and similar treatment of spectra in other studies (Hansel et al., 2003). Fit boundaries indicated by dotted lines at $\mathrm{R}=1.2$ and 4 . Calculated fitting parameters shown in Table 3.

At the halfway point of reaction C6 at 1 min (Figure 7a), large rod-like particles have formed near the edges of the green rust crystal and a faint boundary can be seen. The interiors of the hexagonal crystals appear fractured (visible in the inset), which may be an artifact of the sample preparation or the vacuum conditions in the sample chamber. The SAED pattern shows the same hexagonally packed oxygen-derived reflections as mentioned earlier. After $10 \mathrm{~min}$, when the reaction is nearing completion, the hexagonal particle morphology is maintained with goethite-like rods associated with the crystal edges and parallel crystal fractures visible in the crystal interior (Figure 7b). SAED patterns obtained from these central domains are faint (possibly due to underexposure) but show the same reflections visible in the $\mathrm{C} 1$ samples. SEM images also show that these particles have smooth surfaces. After 7 days, the hexagonal particles have lost much of their crystallinity, with degraded edges and a few goethite-like rods associated with the structure (Figure 7c). Very faint spots are visible in the 
diffraction pattern. As aging processes are not known to transform crystalline materials to amorphous analogues, even topotactically, a more likely explanation is that residual Fe(II) in the system induced the crystallization of particles in earlier $(1 \mathrm{~min}, 10 \mathrm{~min})$ samples by the mechanism identified in Pedersen et al. (2005) [42], whereas Fe(II) is absent after 7 days of reaction time. Pedersen et al. [42] proposed that electron conduction from aqueous $\mathrm{Fe}^{2+}$ gives rise to $\mathrm{Fe}(\mathrm{II})-\mathrm{O}$ bonds in the interior of ferrihydrite, which destabilizes the structure and leads to dissolution and re-precipitation, but the generation of structural Fe(II) would stabilize these LDH-like particles, in which $\mathrm{Fe}(\mathrm{II})-\mathrm{O}_{6}$ octahedra are more stable. The oxidation of the remaining structural Fe(II), however, leads to a restructuring of the LDH-like particles, which have low crystallinity after the reaction is complete.

(a

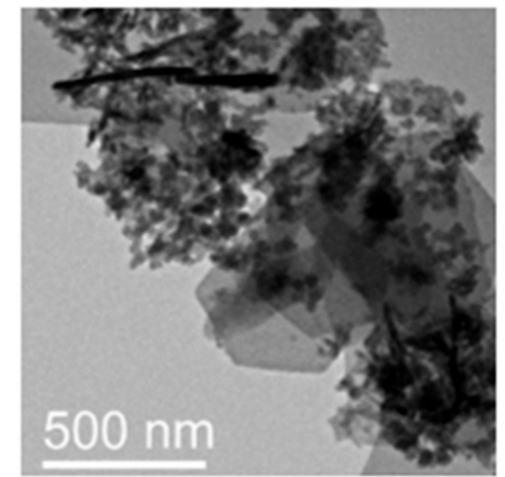

(b
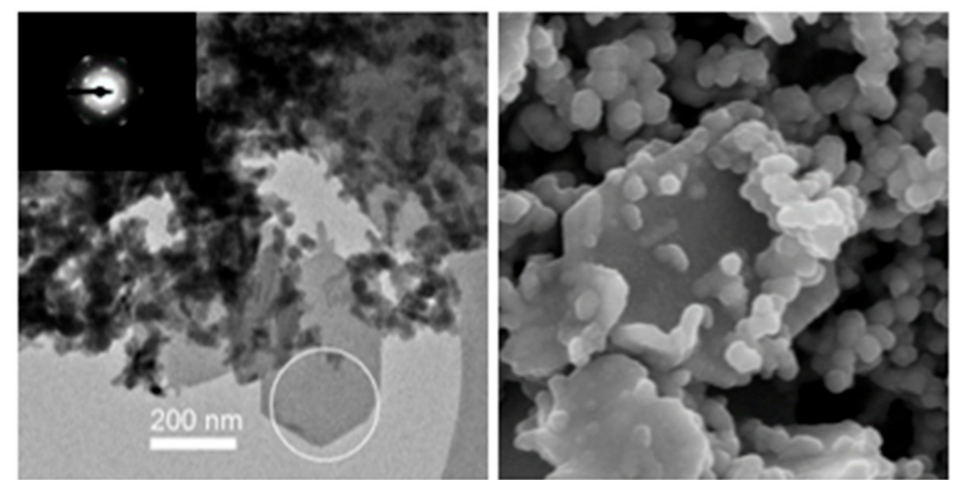

(c
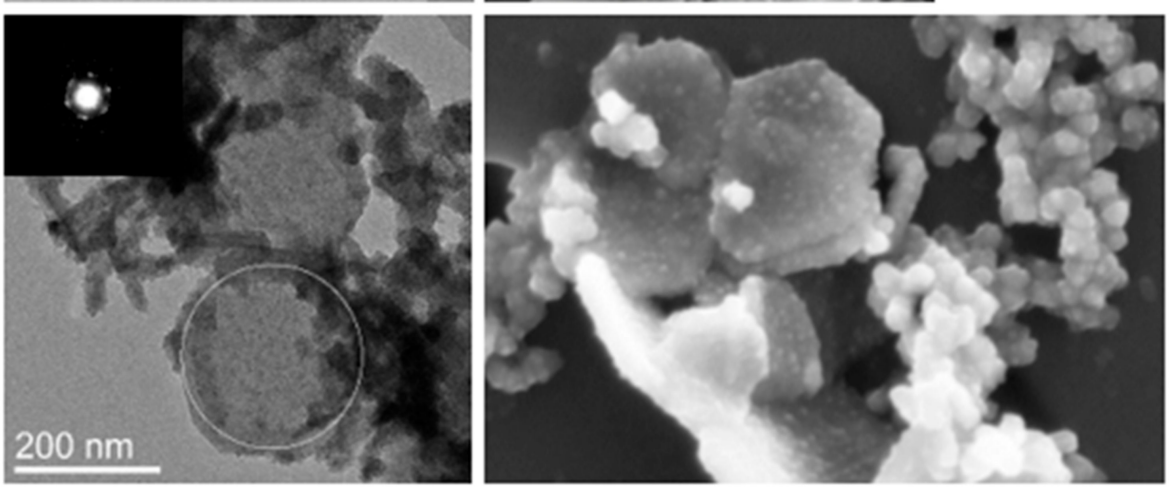

Figure 6. SEM and TEM images showing the progression of reaction $\mathrm{C} 1$ after $5 \mathrm{~s} \mathrm{(a),} 1 \mathrm{~min}(\mathbf{b})$ and 7 days (c) of reaction time. Regions where electron diffraction measurements were obtained are circled, and the diffraction patterns are shown in the insets. Spacings of 2.5 and $1.7 \AA$ detected after 1 min, very weak pattern detected after 7 days. 
(a
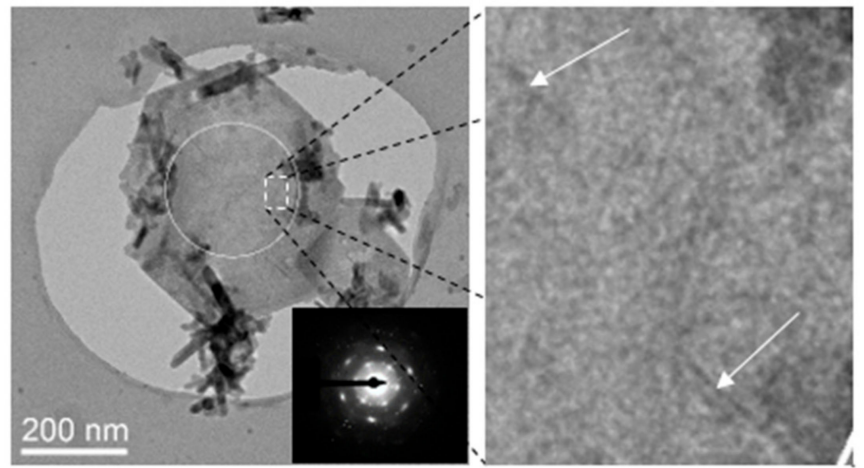

(b
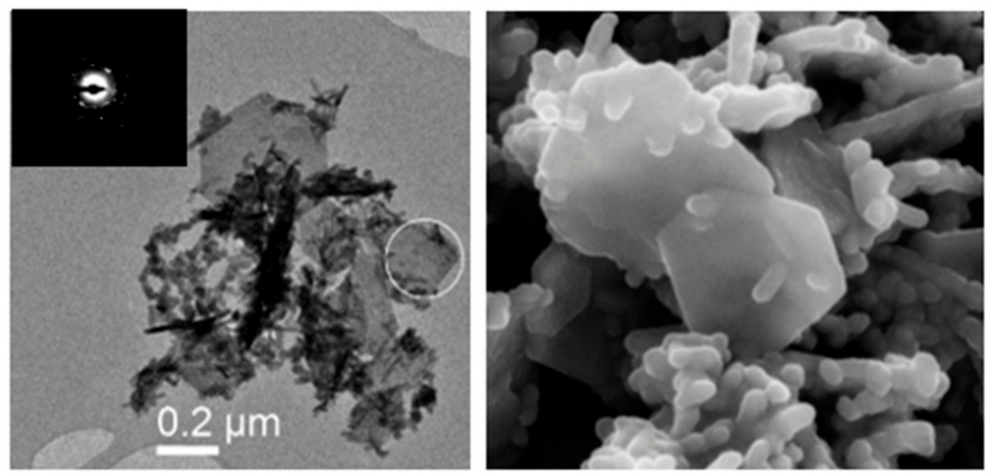

(c
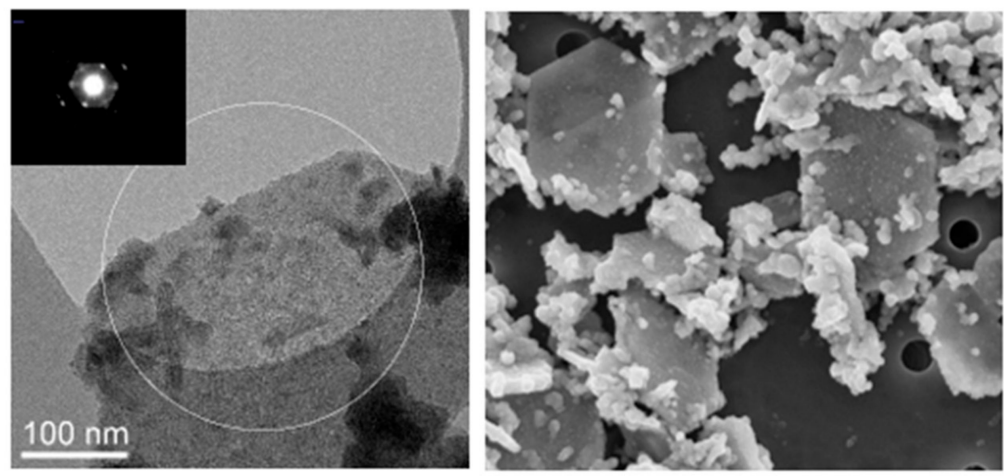

Figure 7. SEM and TEM images showing the progression of reaction C6 after $1 \mathrm{~min}(\mathbf{a}), 10 \mathrm{~min}(\mathbf{b})$ and 7 days (c) of reaction time. Regions where electron diffraction measurements were obtained are circled. Spacings of 2.5 and $1.7 \AA$ detected after $1 \mathrm{~min}$ and $10 \mathrm{~min}$, very faint rings after 7 days.

\section{Discussion}

\subsection{Kinetics of $\mathrm{CrO}_{4}{ }^{2-}$ Reduction by Green Rust Sulfate}

Reaction rates in this study were much faster than those observed by Bond and Fendorf (2003) [28] for a reaction between $\mathrm{CrO}_{4}{ }^{2-}$ and green rust sulfate at similar concentrations. Skovbjerg et al. (2006) [31] also observed rapid reduction of $\mathrm{CrO}_{4}{ }^{2-}$ and attributed the difference to the method of preparation. Drying synthetic green rust dehydrates the interlayer, which is hypothesized to decrease the exchangeability and reactivity of oxidants [14]. The green rust in this experiment was not dried or rinsed after synthesis.

Since the green rust was added as a suspension, aqueous $\mathrm{Fe}^{2+}$ was present at the beginning of the reaction, but at a low concentration. The resulting reaction between $\mathrm{CrO}_{4}{ }^{2-}$ and $\mathrm{Fe}^{2+}$ may have been the reason for a $\mathrm{pH}$ drop to between 4 and 5 in each experiment. However, previous studies $[43,44]$ suggest that the reduction rate of $\mathrm{CrO}_{4}{ }^{2-}$ by aqueous $\mathrm{Fe}^{2+}$ is rapid enough to contribute to the reaction kinetics observed in this experiment, but this reaction rate is heavily dependent on $\mathrm{pH}$, the behavior of which was not monitored while the reaction was in progress. It is possible that the green rust surface may have acted as a substrate, increasing the rate of reduction [31]. 


\subsection{Composition of Observed Reaction Products}

Fe EXAFS fitting results reveal that the short-range (5-6 $\AA$ ) particle structure is dominated by feroxyhyte-like structural motifs (i.e., face-sharing octahedra). The Fourier-transformed Cr spectra show a prominent single corner-sharing shell at an interatomic distance of approximately $3.9 \AA$, characteristic of a $\gamma-\mathrm{CrOOH}$ short-range structure (Figure 8), a structure typical of poorly crystalline Cr hydroxides [38-40]. Charlet \& Manceau (1992) [39] showed that EXAFS spectra of Cr coprecipitated with Fe or sorbed on Fe oxide surfaces show a double corner-sharing reflection at approximately $3.46 \AA$, which was not detected in the current study. This suggests that the $\mathrm{Cr}$ in these samples has formed a spatially distinct $\mathrm{Cr}(\mathrm{III})$ hydroxide phase, probably precipitated on the surface of Fe oxide particles. These results, combined with electron microscopy images that show that the hexagonal morphology of the green rust crystals is maintained after oxidation, suggest that the primary product is a layered $\mathrm{Fe}(\mathrm{III})$ oxyhydroxysulfate with a spatially distinct $\mathrm{Cr}(\mathrm{OH})_{3}$ phase that forms on the particle surface or in the bulk solution.

Ferrihydrite and feroxyhyte are nano-crystalline Fe oxides. Based on published structures $[36,45,46]$, both phases would be expected to give rise to the hexagonal arranged diffraction spots identified with SAED when probed perpendicular to the hexagon oxygen packing. As EXAFS is a short-range $(<5-6 \AA)$ technique and is unable to detect long-range crystal structure, the detection of material with a feroxyhyte- or ferrihydrite-like structure is most likely an expression of structural motifs present in both the synthesized feroxyhyte reference standard and the product. EDX spectra of these hexagonal particles also revealed unexpectedly high sulfur concentrations, indicating that sulfate is still incorporated into the structure. Rapid oxidation of the green rust crystal without displacing the interlayer sulfate anions would prevent complete transformation to another $\mathrm{Fe}$ (III) oxide, potentially explaining why the primary product is poorly crystalline. A topotactic redox reaction would require partial deprotonation of the Fe oxide layers to maintain the charge balance; one way this could be accomplished is the formation of the face-sharing octahedra suggested by the EXAFS fitting results. Previous studies $[47,48]$ have claimed that a major product of rapid oxidation of green rust sulfate is a layered, poorly crystalline $\mathrm{Fe}(\mathrm{III})$ oxyhydroxysulfate, and the product of the reaction in this study appears to be similar.

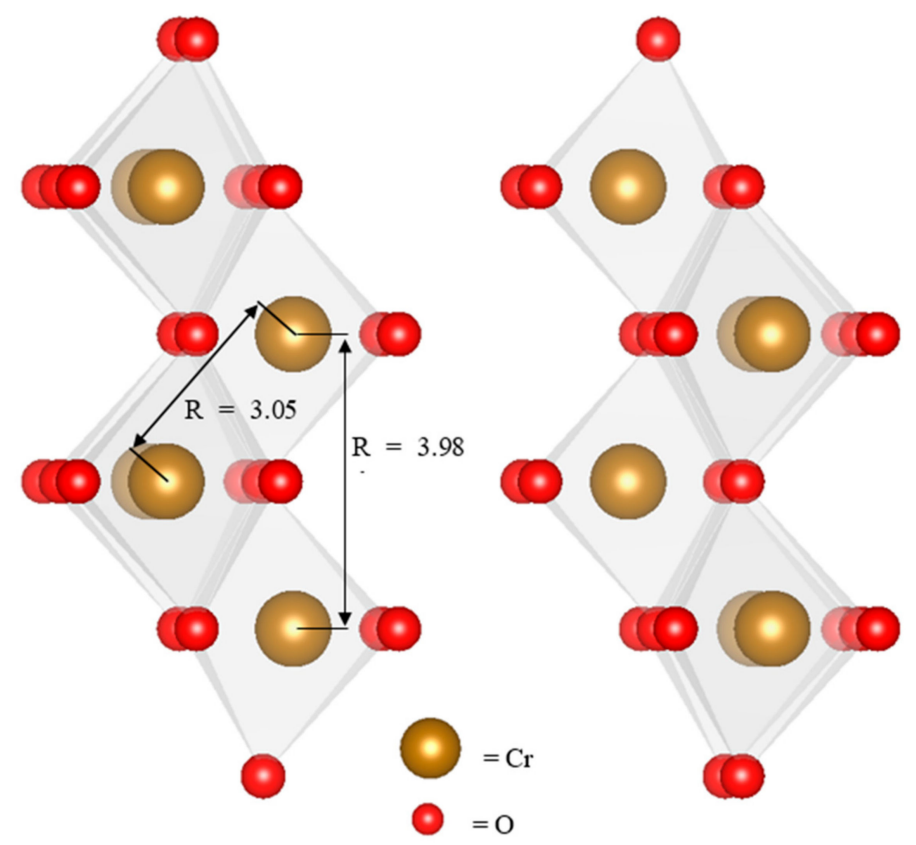

Figure 8. $\Gamma$ - $\mathrm{CrOOH}$ short-range structure of $\mathrm{Cr}(\mathrm{OH})_{3}$. Edge-sharing $(3.05 \AA$ ) and single corner-sharing (3.98 A) $\mathrm{Cr}-\mathrm{Cr}$ distances correspond to the predominant scattering paths identified by EXAFS fitting. 
Spectroscopic data also suggests that lepidocrocite and goethite are significant components of the byproduct. Needle- and rod-like particles with lengths of approximately 50 nanometers and similar morphologies to goethite are visible in TEM and SEM images, both on the hexagonal particle surfaces (see SEM images) and in separate aggregates. Sharply defined rod-like particles are no longer present after 7 days. Skovbjerg et al. (2006) [31] identified $\mathrm{Cr}$ (III)-bearing goethite as the primary product of this reaction, and the low crystallinity of the product in both experiments is most likely a result of $\mathrm{Cr}$ substitution for Fe [49]. These particles likely formed through a dissolution-precipitation mechanism while the product was aging and nucleated on the hexagonal particle surfaces or in the bulk solution. Lepidocrocite was also detected in samples obtained from reactions at lower chromate concentrations, possibly due to the formation of lepidocrocite-like structural motifs (i.e., edge-sharing octahedra) within the layered, poorly crystalline final product.

Amorphous particles can also be seen in aggregates separate from the hexagonal particles. These particles appear circular in TEM and SEM images and have very high $\mathrm{Cr}$ concentrations. EDX measurements show that $\mathrm{Cr} /(\mathrm{Fe}+\mathrm{Cr})$ is between 20 and $40 \%$, so these particles most likely formed due to reduction of chromate by aqueous $\mathrm{Fe}^{2+}$. The stoichiometry of this reaction (Equation (1)) results in particles with very high $\mathrm{Cr}$ content.

$$
0.25 \mathrm{CrO}_{4}^{2-}+0.75 \mathrm{Fe}^{2+}+2 \mathrm{H}_{2} \mathrm{O}=\mathrm{Cr}_{0.25} \mathrm{Fe}_{0.75}(\mathrm{OH})_{3}+\mathrm{H}^{+}
$$

Although the rate of this reaction is $\mathrm{pH}$-dependent $[43,44]$ and therefore unknown, the visibility of these particles suggests that this reaction contributed to $\mathrm{Cr}(\mathrm{VI})$ reduction and green rust may have acted as a reaction substrate. Schwertmannite formation is favored by the conditions observed at the end of the reaction, so a substantial portion of the amorphous particles may be identified as schwertmannite.

\subsection{Reaction Mechanisms}

As the poorly crystalline particles observed at the end of the reaction maintain their hexagonal morphologies, are feroxyhyte-like in structure and still contain sulfur, these particles were most likely to have been oxidized by means of $\mathrm{CrO}_{4}{ }^{2-}$ reduction at the particle surface, which oxidizes $\mathrm{Fe}(\mathrm{II})$ in the interior via an electron hopping mechanism. Green rust, like many other Fe(III) oxides [50,51], is a semiconductor due to the ability of electrons to migrate between adjacent $\mathrm{Fe}$ (II) centers [52]. This electron hopping is fastest for electron transport within an $\mathrm{Fe}(\mathrm{II}) / \mathrm{Fe}(\mathrm{III})$ oxide layer, but Yao et al. (1998) [53] demonstrated that electron transport between layers is possible in green rusts and other LDHs and accelerates in response to the introduction of a potential difference (i.e., binding of chromate at the particle surface). Through this mechanism, green rust can regenerate reactive Fe(II) centers at the surface by transporting the electron "holes" produced by oxidation into the crystal's interior, which then causes a rearrangement to another Fe(III) oxide structure to balance the charge. The Fe(III) oxide produced depends on the oxidation rate; Hansen (2001) [54] gave the following succession from slow to fast reaction: magnetite, goethite, lepidocrocite, feroxyhyte and ferrihydrite. However, this mechanism, especially when rapid, may not allow the sulfate in the interlayer to escape, with the resulting charge imbalance preventing complete transformation of the product to a thermodynamically preferred crystalline Fe oxide. The partially transformed Fe(III) oxide resembled feroxyhyte and lepidocrocite spectroscopically because the layered structure was maintained, and most transformations involved deprotonation and formation of face-sharing octahedra to balance the charge. The spectroscopic resemblance of the product to feroxyhyte is most likely a consequence of this type of internal rearrangement.

The other major product of this surface oxidation reaction is the amorphous $\mathrm{Cr}(\mathrm{OH})_{3}$ coating. This coating forms because poorly crystalline Fe(III) oxide surfaces are ideal substrates for $\mathrm{Cr}$ (III) precipitation [39,55], and newly produced $\mathrm{Cr}^{3+}$ ions continue to precipitate as $\mathrm{Cr}(\mathrm{OH})_{3}$ at the particle surface. This $\mathrm{Cr}(\mathrm{III})$ oxyhydroxide layer passivates the surface by blocking access to the green rust structure, as observed when chromate reacts with other green rusts [30], magnetite [56] and ZVI [57]. 
Passivation may be responsible for the incomplete reduction of chromate in reactions C4-C6, where $10 \%$ of the chromate remains in solution at the end of the reaction.

In addition to the coated hexagonal plates, the reaction also produced rod-like particles of goethite, which can be seen in the SEM and TEM images and detected in the Fe and Cr EXAFS spectra. Skovbjerg et al. (2006) [30] identified similar Cr(III)-bearing goethites and hypothesized that these particles formed as a result of green rust oxidation through a chromate-sulfate interlayer exchange mechanism. The stoichiometry of this reaction predicts a $\mathrm{Cr}(\mathrm{III})$-goethite solid solution with a $\mathrm{Cr} /(\mathrm{Cr}+\mathrm{Fe})$ ratio of 0.182 (Equation (2)).

$$
0.75 \mathrm{Fe}_{4}^{\mathrm{II}} \mathrm{Fe}_{2}^{\mathrm{III}}(\mathrm{OH})_{12} \mathrm{SO}_{4} \cdot 8 \mathrm{H}_{2} \mathrm{O}+\mathrm{CrO}_{4}^{2-}+0.5 \mathrm{H}^{+}=5.5 \mathrm{Fe}_{0.818} \mathrm{Cr}_{0.182} \mathrm{OOH}+0.75 \mathrm{SO}_{4}^{2-}+8 \mathrm{H}_{2} \mathrm{O}
$$

Schwertmann et al. (1989) [49] were not able to synthesize goethite with $\mathrm{Cr} /(\mathrm{Cr}+\mathrm{Fe})$ mole ratios greater than 0.12 , and Skovbjerg et al. (2006) [31] found that goethite particles with $\mathrm{Cr} /(\mathrm{Cr}+\mathrm{Fe})$ greater than approximately 0.10 (as measured by EDX) underwent rearrangement and became less crystalline as the product was aged. Similarly, goethite particles produced in reactions C1 and C6 appear crystalline early in the reaction but poorly crystalline in TEM images (Figures 6 and 7) after aging the product for seven days, and the goethite component of both the Fe and Cr EXAFS fits appears to decline between $24 \mathrm{~h}$ and 7 days, indicating that these particles may be losing their crystallinity. A more likely explanation is the depletion of aqueous $\mathrm{Fe}^{2+}$, which has been shown to catalyze the transformation of poorly crystalline Fe(III) oxyhydroxides in batch and flow-through experiments $[58,59]$.

The most noticeable trend in these experiments is that more goethite is produced at higher initial $\mathrm{CrO}_{4}{ }^{2-}$ concentrations. This trend matches the observations of Skovbjerg et al. (2006) [31], where $\mathrm{Cr}$-substituted goethite is the primary product of reactions with much higher initial $\mathrm{CrO}_{4}{ }^{2-}$ concentrations, while Bond and Fendorf (2003) [28] observed the formation of an amorphous product at concentrations similar to those tested in this experiment. Therefore, it appears that the $\mathrm{CrO}_{4}{ }^{2-}$ exchange mechanism becomes more important to the reaction at higher $\mathrm{CrO}_{4}{ }^{2-}$ concentrations. Equations (3) and (4) show the rate-limiting steps of the competing exchange and surface oxidation (assuming monodentate adsorption of $\mathrm{Cr}(\mathrm{VI})$ ) mechanisms, as well as the hypothetical rate equations of these reactions. If the $\mathrm{CrO}_{4}{ }^{2-}$ reaction order $(a)$ of the exchange reaction is higher than the reaction order $(c)$ of the surface oxidation reaction, this would cause $\mathrm{Cr}$-substituted goethite to be favored at higher $\mathrm{CrO}_{4}{ }^{2-}$ concentrations as observed.

$$
\begin{gathered}
\mathrm{CrO}_{4}^{2-}+\mathrm{GR}-\mathrm{SO}_{4}=\mathrm{GR}-\mathrm{CrO}_{4}+\mathrm{SO}_{4}^{2-} \frac{\mathrm{d}\left[\mathrm{CrO}_{4}^{2-}\right]}{\mathrm{dt}}=\mathrm{k}_{1} \frac{\left[\mathrm{CrO}_{4}^{2-}\right]^{\mathrm{a}}}{\left[\mathrm{SO}_{4}^{2-}\right]^{\mathrm{b}}} \\
\mathrm{CrO}_{4}^{2-}+\mathrm{FeOH}=\mathrm{FeOCrO}_{3}^{-}+\mathrm{OH}^{-} \cdot \frac{\mathrm{d}\left[\mathrm{CrO}_{4}^{2-}\right]}{\mathrm{dt}}=\mathrm{k}_{2} \frac{\left[\mathrm{CrO}_{4}^{2-}\right]^{\mathrm{c}}}{\left[\mathrm{OH}^{-}\right]^{\mathrm{d}}}
\end{gathered}
$$

\subsection{Implications for Use in Permeable Reactive Barriers}

The effectiveness of green rust sulfate for reducing $\mathrm{Cr}(\mathrm{VI})$ has been addressed by these experiments, but the long-term stability of the $\mathrm{Cr}(\mathrm{III})$-bearing products of this reaction remains questionable. Due to the heterogeneity of the reaction between green rust sulfate particles and aqueous $\mathrm{CrO}_{4}{ }^{2-}$, the identity and morphology of the products depend on the mechanism and can therefore be changed by modifications to the particle composition. The primary product of these reactions was a hexagonal, $\mathrm{Fe}(\mathrm{III})$ oxyhydroxysulfate particle covered by a $\mathrm{Cr}(\mathrm{OH})_{3}$ surface coating. $\mathrm{Cr}(\mathrm{III})$ oxyhydroxides are poorly characterized, but Papassiopi et al. (2014) [60] found that synthetic $\mathrm{Cr}(\mathrm{OH})_{3}$ is more soluble than its $\mathrm{Fe}(\mathrm{III})$ analogue and did not transform to a less-soluble $\mathrm{Cr}$ (oxy)hydroxide during the experiment. Because $\mathrm{CrO}_{4}{ }^{2-}$ is normally found under oxidizing conditions, $\mathrm{Cr}(\mathrm{OH})_{3}$ 
dissolution is a potential pathway for the return of $\mathrm{CrO}_{4}{ }^{2-}$ to the newly remediated groundwater if the redox conditions have not been altered, particularly in the presence of $\mathrm{Mn}$ (IV) oxides [61]. Studies of $\mathrm{Cr}(\mathrm{III})$ hydroxide redox behavior in soils [9-11,62] have shown that biogenic Mn(IV) oxides in soils can reverse the reductive transformation of chromate by oxidizing soluble $\mathrm{Cr}^{3+}$. The limiting factor in this process is the solubility of the $\mathrm{Cr}(\mathrm{III})$-bearing phases (incorporation into ferrihydrite decreased oxidation by $37 \%$ ), so the product produced in these reactions suggests that this method is unsuitable. In addition, green rust sulfate is unstable under oxidizing conditions, and modifications to the structure or composition to prevent oxidation by other compounds might make green rust sulfate more viable for remediation. Green rust is also metastable with respect to magnetite and transforms to magnetite when diluted in water, suggesting that it may not be stable under flow conditions in aquifers unless stabilized by high $\mathrm{Fe}^{2+}$ concentrations in the groundwater [62].

Similarly, this study provides insights into the chemical and microbial mechanisms governing $\mathrm{Cr}$ speciation in natural environments. Green rust is commonly encountered in redox transition-zone sediments [13] and is believed to form as a result of microbial bioreduction of Fe oxides [63,64], and reduction by green rust and other Fe(II)-bearing minerals is most likely one of the mechanisms governing changes in $\mathrm{Cr}$ speciation in response to soil redox conditions. Reduction of $\mathrm{Cr}(\mathrm{VI})$ by structural $\mathrm{Fe}(\mathrm{II})$ in biogenic Fe oxides may favor the precipitation of spatially distinct $\mathrm{Cr}$ (III) hydroxides in soils.

\section{Conclusions}

This study shows that green rust sulfate can effectively remediate $\mathrm{Cr}(\mathrm{VI})$ contamination in groundwater, but the investigators have concerns about the stability of the reaction byproducts. Based on the EXAFS fitting results (Figures 4 and 5, Tables 2 and 3) and electron microscope images (Figures 6 and 7), it appears that this reaction produces a poorly crystalline $\mathrm{Cr}(\mathrm{III})$ hydroxide, as opposed to a $\mathrm{Cr}$ (III)-substituted Fe oxide, which would be far more stable and resistant to oxidation by $\mathrm{Mn}(\mathrm{IV})$ oxides. One potential pathway for future study is the use of green rust solid solutions to remediate $\mathrm{Cr}(\mathrm{VI})$. $\mathrm{Cr}(\mathrm{III})$-substituted $\mathrm{Fe}(\mathrm{III})$ oxides should be viewed as the favored products of this reaction due to their increased stabilities; therefore, particles should be designed to favor the $\mathrm{CrO}_{4}{ }^{2-}$ exchange reduction mechanism. Substitutions of metal cations such as $\mathrm{Zn}, \mathrm{Mg}$, and $\mathrm{Al}$ that do not have multiple oxidation states may disrupt the electron hopping chain that enables reduction of $\mathrm{CrO}_{4}{ }^{2-}$ at the particle surface. These particles may also be more stable than pure green rust if $\mathrm{O}_{2}$ is unable to oxidize them at their surfaces.

Supplementary Materials: The following are available online at http:/ /www.mdpi.com/2571-8789/2/4/58/s1. A more detailed description of the green rust synthesis and XAS data analysis procedures, as well as $\mathrm{Cr}$ reference standard synthesis methods and LCF fit statistics, can be found in the attached supplementary materials.

Author Contributions: Conceptualization, A.N.T., K.D. and T.N.; methodology, A.N.T., E.E. and T.N.; validation, T.N., K.D. and L.G.B.; investigation, A.N.T., J.G., R.S. and H.M.F.; resources, E.E., L.G.B. and T.N.; writing-original draft preparation, A.N.T.; writing-review and editing, E.E., L.G.B., H.M.F., K.D. and T.N.; visualization, A.N.T. and H.M.F.; supervision, T.N.; funding acquisition, L.G.B., K.D. and T.N.

Funding: This project has received funding from the European Union's Horizon 2020 research and innovation programme under the Marie Skłodowska-Curie grant agreement No. 675219 and from the German Helmholtz Recruiting Initiative (award number I-044-16-01) (LGB and HF).

Acknowledgments: We would like to thank the other members of the Aquatic Geochemistry group at KIT for their technical assistance and comments on this ongoing work. We would also like to thank the staff of the Interface Geochemistry group at GFZ (particularly Sathish Mayanna) and the ANKA synchrotron facility for use of their instruments and technical assistance.

Conflicts of Interest: The authors declare no conflict of interest.

\section{References}

1. Saha, R.; Nandi, R.; Saha, B. Sources and toxicity of hexavalent chromium. J. Coord. Chem. 2011, 64, 1782-1806. [CrossRef] 
2. Barceloux, D.G. Chromium. J. Toxicol. Clin. Toxicol. 1999, 37, 173-194. [CrossRef] [PubMed]

3. Rai, D.; Sass, B.M.; Moore, D.A. Chromium(III) Hydrolysis Constants and Solubility of Chromium(III) Hydroxide. Inorg. Chem. 1987, 26, 345-349. [CrossRef]

4. Rai, D.; Moore, D.A.; Hess, N.J.; Rosso, K.M.; Rao, L.; Heald, S.M. Chromium(III) Hydroxide Solubility in the Aqueous $\mathrm{K}^{+}-\mathrm{H}^{+}-\mathrm{OH}^{-}-\mathrm{CO}_{2}-\mathrm{HCO}_{3}{ }^{-}-\mathrm{CO}_{3}{ }^{2-}-\mathrm{H}_{2} \mathrm{O}$ System: A Thermodynamic Model. J. Solut. Chem. 2007, 36, 1261-1285. [CrossRef]

5. Su, C.; Ludwig, R.D. Treatment of Hexavalent Chromium in Chromite Ore Processing Solid Waste Using a Mixed Reductant Solution of Ferrous Sulfate and Sodium Dithionite. Environ. Sci. Technol. 2005, 39, 6208-6216. [CrossRef] [PubMed]

6. Puls, R.W.; Paul, C.J.; Powell, R.M. The application of in situ permeable reactive (zero-valent iron) barrier technology for the remediation of chromate-contaminated groundwater: A field test. Appl. Geochem. 1999, 14, 989-1000. [CrossRef]

7. Wilkin, R.T.; Su, C.; Ford, R.G.; Paul, C.J. Chromium-Removal Processes during Groundwater Remediation by a Zerovalent Iron Permeable Reactive Barrier. Environ. Sci. Technol. 2005, 39, 4599-4605. [CrossRef] [PubMed]

8. Kumpiene, J.; Ore, S.; Renella, G.; Mench, M.; Lagerkvist, A.; Maurice, C. Assessment of zerovalent iron for stabilization of chromium, copper, and arsenic in soil. Environ. Pollut. 2006, 144, 62-69. [CrossRef] [PubMed]

9. Hausladen, D.M.; Fendorf, S. Hexavalent Chromium Generation within Naturally Structured Soils and Sediments. Environ. Sci. Technol. 2017, 51, 2058-2067. [CrossRef] [PubMed]

10. Pan, C.; Liu, H.; Catalano, J.G.; Qian, A.; Wang, Z.; Giammar, D.E. Rates of Cr(VI) Generation from $\mathrm{Cr}_{\mathrm{x}} \mathrm{Fe}_{1-\mathrm{x}}(\mathrm{OH})_{3}$ Solids upon Reaction with Manganese Oxide. Environ. Sci. Technol. 2017, 51, 12416-12423. [CrossRef] [PubMed]

11. Varadharajan, C.; Beller, H.R.; Bill, M.; Brodie, E.L.; Conrad, M.E.; Han, R.; Irwin, C.; Larsen, J.T.; Lim, H.C.; Molins, S.; et al. Reoxidation of Chromium(III) Products Formed under Different Biogeochemical Regimes. Environ. Sci. Technol. 2017, 51, 4918-4927. [CrossRef] [PubMed]

12. Christiansen, B.C.; Dideriksen, K.; Katz, A.; Nedel, S.; Bovet, N.; Sorensen, H.O.; Frandsen, C.; Gundlach, C.; Andersson, M.P.; Stipp, S.L. Incorporation of monovalent cations in sulfate green rust. Inorg. Chem. 2014, 53, 8887-8894. [CrossRef] [PubMed]

13. Trolard, F.; Bourrié, G.; Abdelmoula, M.; Refait, P.; Feder, F. Fougerite, a new mineral of the pyroaurite-iowaite group: Description and crystal structure. Clays Clay Miner. 2007, 55, 323-334. [CrossRef]

14. Lewis, D.G. Factors influencing the stability and properties of green rusts. Adv. Geoecol. 1997, 30, 345-372.

15. Roh, Y.; Lee, S.Y.; Elless, M.P. Characterization of corrosion products in the permeable reactive barriers. Environ. Geol. 2000, 40, 184-194. [CrossRef]

16. Refait, P.; Memet, J.B.; Bon, C.; Sabot, R.; Génin, J.M.R. Formation of the Fe(II)-Fe(III) hydroxysulphate green rust during marine corrosion of steel. Corros. Sci. 2003, 45, 833-845. [CrossRef]

17. Su, C.; Puls, R.W. Significance of Iron(II,III) Hydroxycarbonate Green Rust in Arsenic Remediation Using Zerovalent Iron in Laboratory Column Tests. Environ. Sci. Technol. 2004, 38, 5224-5231. [CrossRef] [PubMed]

18. Jönsson, J.; Sherman, D.M. Sorption of As(III) and As(V) to siderite, green rust (fougerite) and magnetite: Implications for arsenic release in anoxic groundwaters. Chem. Geol. 2008, 255, 173-181. [CrossRef]

19. Perez, J.P.H.; Freeman, H.M.; Schuessler, J.A.; Benning, L.G. The interfacial reactivity of arsenic species with green rust sulfate $\left(\mathrm{GR}_{\mathrm{SO} 4}\right)$. Sci. Total Environ. 2019, 648, 1161-1170. [CrossRef] [PubMed]

20. Hansen, H. Kinetics of nitrate reduction by green rusts-Effects of interlayer anion and Fe(II):Fe(III) ratio. Appl. Clay Sci. 2001, 18, 81-91. [CrossRef]

21. Hansen, H.C.B.; Borggaard, O.K.; Sørensen, J. Evaluation of the free energy of formation of Fe(II)-Fe(III) hydroxide-sulphate (green rust) and its reduction of nitrite. Geochim. Cosmochim. Acta 1994, 58, 2599-2608. [CrossRef]

22. Myneni, S.C. Abiotic Selenium Redox Transformations in the Presence of Fe(II,III) Oxides. Science 1997, 278, 1106-1109. [CrossRef]

23. Borsig, N.; Scheinost, A.C.; Shaw, S.; Schild, D.; Neumann, T. Retention and multiphase transformation of selenium oxyanions during the formation of magnetite via iron(II) hydroxide and green rust. Dalton Trans. 2018, 47, 11002-11015. [CrossRef] [PubMed] 
24. O'Loughlin, E.J.; Kelly, S.D.; Cook, R.E.; Csencsits, R.; Kemner, K.M. Reduction of Uranium(VI) by Mixed

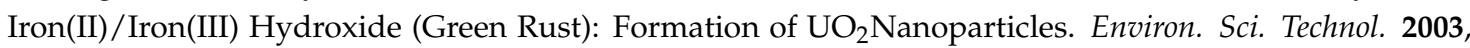
37, 721-727. [CrossRef] [PubMed]

25. Christiansen, B.C.; Geckeis, H.; Marquardt, C.M.; Bauer, A.; Römer, J.; Wiss, T.; Schild, D.; Stipp, S.L.S. Neptunyl (Np) interaction with green rust. Geochim. Cosmochim. Acta 2011, 75, 1216-1226. [CrossRef]

26. Loyaux-Lawniczak, S.; Refait, P.; Lecomte, P.; Ehrhardt, J.J.; Génin, J.M.R. The reduction of chromate ions by Fe(II) layered hydroxides. Hydrol. Earth Syst. Sci. 1999, 3, 593-599. [CrossRef]

27. Loyaux-Lawniczak, S.; Refait, P.; Ehrhardt, J.-J.; Lecomte, P.; Génin, J.-M.R. Trapping of Cr by Formation of Ferrihydrite during the Reduction of Chromate Ions by $\mathrm{Fe}(\mathrm{II})-\mathrm{Fe}(\mathrm{III})$ Hydroxysalt Green Rusts. Environ. Sci. Technol. 2000, 34, 438-443. [CrossRef]

28. Bond, D.L.; Fendorf, S. Kinetics and Structural Constraints of Chromate Reduction by Green Rusts. Environ. Sci. Technol. 2003, 37, 2750-2757. [CrossRef] [PubMed]

29. Williams, A.G.B.; Scherer, M.M. Kinetics of Cr(VI) Reduction by Carbonate Green Rust. Environ. Sci. Technol. 2001, 35, 3488-3494. [CrossRef] [PubMed]

30. Legrand, L.; El Figuigui, A.; Mercier, F.; Chausse, A. Reduction of Aqueous Chromate by Fe(II)/Fe(III) Carbonate Green Rust: Kinetic and Mechanistic Studies. Environ. Sci. Technol. 2004, 38, 4587-4595. [CrossRef] [PubMed]

31. Skovbjerg, L.L.; Stipp, S.L.S.; Utsunomiya, S.; Ewing, R.C. The mechanisms of reduction of hexavalent chromium by green rust sodium sulphate: Formation of Cr-goethite. Geochim. Cosmochim. Acta 2006, 70, 3582-3592. [CrossRef]

32. Géhin, A.; Ruby, C.; Abdelmoula, M.; Benali, O.; Ghanbaja, J.; Refait, P.; Génin, J.-M.R. Synthesis of Fe(II-III) hydroxysulphate green rust by coprecipitation. Solid State Sci. 2002, 4, 61-66. [CrossRef]

33. Ravel, B.; Newville, M. ATHENA and ARTEMIS Interactive Graphical Data Analysisusing IFEFFIT. Physica Scr. 2005, 12, 537-541. [CrossRef]

34. Cornell, R.M.; Schwertmann, U. Iron Oxides in the Laboratory, 2nd ed.; Wiley-VCH: Weinheim, Germany, 2008.

35. Simon, L.; François, M.; Refait, P.; Renaudin, G.; Lelaurain, M.; Génin, J.-M.R. Structure of the Fe(II-III) layered double hydroxysulphate green rust two from Rietveld analysis. Solid State Sci. 2003, 5, 327-334. [CrossRef]

36. Manceau, A.; Drits, V.A. Local Structure of Ferrihydrite and Feroxyhite by Exafs Spectroscopy. Clay Miner. 2018, 28, 165-184. [CrossRef]

37. Maillot, F.; Morin, G.; Wang, Y.; Bonnin, D.; Ildefonse, P.; Chaneac, C.; Calas, G. New insight into the structure of nanocrystalline ferrihydrite: EXAFS evidence for tetrahedrally coordinated iron(III). Geochim. Cosmochim. Acta 2011, 75, 2708-2720. [CrossRef]

38. Papassiopi, N.; Pinakidou, F.; Katsikini, M.; Antipas, G.S.; Christou, C.; Xenidis, A.; Paloura, E.C. A XAFS study of plain and composite iron(III) and chromium(III) hydroxides. Chemosphere 2014, 111, 169-176. [CrossRef] [PubMed]

39. Charlet, L.; Manceau, A.A. X-ray absorption spectroscopic study of the sorption of $\mathrm{Cr}(\mathrm{III})$ at the oxide-water interface. J. Colloid Interface Sci. 1992, 148, 443-458. [CrossRef]

40. Frommer, J.; Nachtegaal, M.; Czekaj, I.; Kretzschmar, R. The Cr X-ray absorption K-edge structure of poorly crystalline Fe(III)-Cr(III)-oxyhydroxides. Am. Mineral. 2010, 95, 1202-1213. [CrossRef]

41. Christiansen, B.C.; Balic-Zunic, T.; Petit, P.O.; Frandsen, C.; Mørup, S.; Geckeis, H.; Katerinopoulou, A.; Stipp, S.L.S. Composition and structure of an iron-bearing, layered double hydroxide (LDH)—Green rust sodium sulphate. Geochim. Cosmochim. Acta 2009, 73, 3579-3592. [CrossRef]

42. Pedersen, H.D.; Postma, D.; Jakobsen, R.; Larsen, O. Fast transformation of iron oxyhydroxides by the catalytic action of aqueous Fe(II). Geochim. Cosmochim. Acta 2005, 69, 3967-3977. [CrossRef]

43. Buerge, I.J.; Hug, S.J. Kinetics and $\mathrm{pH}$ Dependence of Chromium(VI) Reduction by Iron(II). Environ. Sci. Technol. 1997, 31, 1426-1432. [CrossRef]

44. Sedlak, D.L.; Chan, P.G. Reduction of hexavalent chromium by ferrous iron. Geochim. Cosmochim. Acta 1997, 61, 2185-2192. [CrossRef]

45. Jansen, E.; Kyek, A.; Schäfer, W.; Schwertmann, U. The structure of six-line ferrihydrite. Appl. Phys. A Mater. Sci. Process. 2002, 74, s1004-s1006. [CrossRef] 
46. Michel, F.M.; Ehm, L.; Antao, S.M.; Lee, P.L.; Chupas, P.J.; Liu, G.; Strongin, D.R.; Schoonen, M.A.; Phillips, B.L.; Parise, J.B. The structure of ferrihydrite, a nanocrystalline material. Science 2007, 316, 1726-1729. [CrossRef] [PubMed]

47. Hansen, H.C.B.; Bender Koch, C. Reduction of nitrate to ammonium by sulphate green rust: Activation energy and reaction mechanism. Clay Miner. 1998, 33, 87-101. [CrossRef]

48. Antony, H.; Legrand, L.; Chaussé, A. Carbonate and sulphate green rusts-Mechanisms of oxidation and reduction. Electrochim. Acta 2008, 53, 7146-7156. [CrossRef]

49. Schwertmann, U.; Gasser, U.; Sticher, H. Chromium-for-iron substitution in synthetic goethites. Geochim. Cosmochim. Acta 1989, 53, 1293-1297. [CrossRef]

50. Schrupp, D.; Sing, M.; Tsunekawa, M.; Fujiwara, H.; Kasai, S.; Sekiyama, A.; Suga, S.; Muro, T.; Brabers, V.A.M.; Claessen, R. High-energy photoemission on $\mathrm{Fe}_{3} \mathrm{O}_{4}$ : Small polaron physics and the Verwey transition. Europhys. Lett. 2005, 70, 789-795. [CrossRef]

51. Katz, J.E.; Zhang, X.; Attenkofer, K.; Chapman, K.W.; Frandsen, C.; Zarzycki, P.; Rosso, K.M.; Falcone, R.W.; Waychunas, G.A.; Gilbert, B. Electron small polarons and their mobility in iron (oxyhydr)oxide nanoparticles. Science 2012, 337, 1200-1203. [CrossRef] [PubMed]

52. Wander, M.C.F.; Rosso, K.M.; Schoonen, M.A.A. Structure and Charge Hopping Dynamics in Green Rust. J. Phys. Chem. C 2007, 111, 11414-11423. [CrossRef]

53. Yao, K.; Taniguchi, M.; Nakata, M.; Takahashi, M.; Yamagishi, A. Electrochemical Scanning Tunneling Microscopy Observation of Ordered Surface Layers on an Anionic Clay-Modified Electrode. Langmuir 1998, 14, 2890-2895. [CrossRef]

54. Hansen, H.C.B. Environmental chemistry of iron (II)-iron (III) LDHs (green rusts). In Layered Double Hydroxides: Present and Future; Rives, V., Ed.; Nova Science Publishers Inc.: New York, NY, USA, 2001; pp. 413-434.

55. Garg, A.; Matijevic, E. Preparation and properties of uniformly coated inorganic colloidal particles. 2. Chromium hydrous oxide on hematite. Langmuir 1988, 4, 38-44. [CrossRef]

56. Kendelewicz, T.; Liu, P.; Doyle, C.S.; Brown, G.E. Spectroscopic study of the reaction of aqueous Cr(VI) with $\mathrm{Fe}_{3} \mathrm{O}_{4}$ (111) surfaces. Surf. Sci. 2000, 469, 144-163. [CrossRef]

57. Lai, K.C.K.; Lo, I.M.C. Removal of chromium (VI) by acid-washed zero-valent iron under various groundwater geochemistry conditions. Environ. Sci. Technol. 2008, 42, 1238-1244. [CrossRef] [PubMed]

58. Yang, L.; Steefel, C.I.; Marcus, M.A.; Bargar, J.R. Kinetics of Fe(II)-catalyzed transformation of 6-line ferrihydrite under anaerobic flow conditions. Environ. Sci. Technol. 2010, 44, 5469-5475. [CrossRef] [PubMed]

59. Boland, D.D.; Collins, R.N.; Miller, C.J.; Glover, C.J.; Waite, T.D. Effect of solution and solid-phase conditions on the $\mathrm{Fe}(\mathrm{II})$-accelerated transformation of ferrihydrite to lepidocrocite and goethite. Environ. Sci. Technol. 2014, 48, 5477-5485. [CrossRef] [PubMed]

60. Papassiopi, N.; Vaxevanidou, K.; Christou, C.; Karagianni, E.; Antipas, G.S. Synthesis, characterization and stability of $\mathrm{Cr}(\mathrm{III})$ and Fe(III) hydroxides. J. Hazard. Mater. 2014, 264, 490-497. [CrossRef] [PubMed]

61. Landrot, G.; Ginder-Vogel, M.; Livi, K.; Fitts, J.P.; Sparks, D.L. Chromium(III) oxidation by three poorly-crystalline manganese(IV) oxides. 1. Chromium(III)-oxidizing capacity. Environ. Sci. Technol. 2012, 46, 11594-11600. [CrossRef] [PubMed]

62. Bartlett, R.; James, B. Behavior of chromium in soils: III. Oxidation 1. J. Environ. Qual. 1979, 8, 31-35. [CrossRef]

63. Fredrickson, J.K.; Zachara, J.M.; Kennedy, D.W.; Dong, H.; Onstott, T.C.; Hinman, N.W.; Li, S.-M. Biogenic iron mineralization accompanying the dissimilatory reduction of hydrous ferric oxide by a groundwater bacterium. Geochim. Cosmochim. Acta 1998, 62, 3239-3257. [CrossRef]

64. Ona-Nguema, G.; Abdelmoula, M.; Jorand, F.; Benali, O.; Block, J.-C.; Génin, J.-M.R. Iron(II,III) Hydroxycarbonate Green Rust Formation and Stabilization from Lepidocrocite Bioreduction. Environ. Sci. Technol. 2002, 36, 16-20. [CrossRef] [PubMed]

(C) 2018 by the authors. Licensee MDPI, Basel, Switzerland. This article is an open access article distributed under the terms and conditions of the Creative Commons Attribution (CC BY) license (http:/ / creativecommons.org/licenses/by/4.0/). 